\title{
Meteorites: Messengers from the Early Solar System
}

\author{
Beda A. Hofmann*
}

\begin{abstract}
Meteorites are fragments from solar system bodies, dominantly asteroids. A small fraction is derived from the Moon and from Mars. These rocks tell a rich history of the early solar system and range from solids little changed since the earliest phases of solid matter condensation in the solar nebula (chondrites) to material representing asteroidal metamorphism and melting, impact processes on the Moon and even aqueous alteration near the surface of Mars. Meteorites are very rare. Currently many meteorites result from searches in Antarctica and the hot deserts of North Africa and Arabia. The present high find rate likely represents a unique short-term event, asking for a careful management of this scarce scientific resource.
\end{abstract}

Keywords: Asteroids · Chondrites · Meteorites · Science management · Solar system

\section{Introduction}

Meteorites are solid objects $>10 \mu \mathrm{m}$ in size that have fallen onto planetary surfaces after arrival at escape velocity or higher $\left(11.2 \mathrm{kms}^{-1}\right.$ in the case of the Earth). This definition based on ref. [1] includes meteorites found on the Moon and Mars, but excludes impact ejecta re-entering directly after ejection. Meteorites have long been met by scepticism or sheer disbelief until, around 1800 , a series of observed falls ( $\mathrm{Si}$ ena, Italy 1794; Wold Cottage, England, 1795; L'Aigle, France 1803; Weston, Connecticut, 1807) and associated publications, most notably ref. [2] (summarized in ref. [3]) convinced the scientific establishment and formed the start of the science of meteoritics. ${ }^{[4]}$ It also quite quickly became clear that meteorites are not some kind of atmospheric phenomena or bombs from distant volcanoes, but true extraterrestrial material. Due to the rarity of me- teorites, they rapidly became sought-after oddities incorporated into the natural science collections of Europe's kings and emperors - forming the basis of some of the large meteorite collections still existing in London, ${ }^{[5]}$ Vienna, ${ }^{[6]}$ Berlin $^{[7]}$ and Paris. ${ }^{[8]}$ Early studies of meteorites demonstrated that most of them are texturally and compositionally different from specific terrestrial rocks, yet they mostly contain minerals familiar from Earth, but in unusual abundance and combination. Meteorites remained the only extraterrestrial samples available for scientific study until material was returned by the Apollo and Luna missions in the period from 1969-1976, yielding a total of $382 \mathrm{~kg}$ of lunar samples. Until today, only tiny amounts of cometary dust have been added to this collection of solar system solids returned by space missions.

Much of our understanding of the origin, constitution and age of the solar system is based on meteorite studies. Meteorites provide information on asteroids, Mars and the Moon: Chemical composition, mineralogy, age, collision and fragmentation history, pre-solar system history, aqueous alteration and isotopic heterogeneity are just a few examples of the information that can be obtained. The currently accepted age of the Earth was first calculated based on $\mathrm{Pb}$-isotope systematics of the Cañon Diablo meteorite in 1953.[9] Information for all officially named meteorites is available from the Database of the Meteoritical Society. ${ }^{[10]}$

\section{Sources of Meteorites}

Natural History Museum Bern

Earth Science Department

Bernastrasse 15

$\mathrm{CH}-3005$ Bern

Tel.: +4131350 7240

Fax: + 41313507499

E-mail: beda.hofmann@geo.unibe.ch so chance finds. Harvey H. Nininger (18871986) was the first person to start system- atic searching for meteorites in the US by interrogating farmers. By 1940, half of all known meteorites were a result of his efforts. Still, the rate of new discoveries between 1900 and 1962 averaged only 15 per year. In 1969, the finding of a few meteorites by a Japanese field team in Antarctica marked the beginning of the exploration of the continent for meteorites by Japanese, US, Chinese and European teams. Discoveries in the Antarctic account for the largest number of meteorites.[11] The systematic search for meteorites in hot deserts started in Roosevelt Co, New Mexico ${ }^{[12]}$ and in the Nullarbor Plain of Australia, ${ }^{[13,14]}$ later to be extended to the deserts of North Africa and Arabia.. ${ }^{[3]}$ Since 2000, Northwest Africa (NWA) has become the largest source of meteorites. Due to economic motivation, local inhabitants of northern African desert countries have successfully started to search for meteorites. Marketing is organized largely through channels long established for the trade of minerals and fossils in Morocco. This new and large source of meteorites has led to the discovery of a number of extremely rare and new meteorite types. Between 2000 and 2010, the average rate of new discoveries increased to 1700 per year (based on ref. [10]), a more than 100-fold increase when compared with the first half of the 20th century. The drawback of this bounty is a near-complete lack of background information concerning find locations of NWA meteorites. Meteorites are typically named after their find location (or find region, for dense collection areas). Due to the impossibility to recognize pairings (meteorites belonging to a single fall event) based on find locations for undocumented meteorites, much scientific effort is wasted for multiple classifications of the same material going through different 
channels. The majority of ordinary chondrites are no longer classified. Thus it will never be possible to obtain proper statistics, such as abundance of certain meteorite types among the large number of NWA. Since 2001, meteorite searches are jointly conducted by Swiss and Omani geologists in the Sultanate of Oman with the aim to provide a well-documented collection of hot desert meteorites. ${ }^{[15,16]}$

\section{Fall Phenomena and Arguments for a Solar System Origin}

One of the main reasons for the fascination brought about by meteorites are the spectacular effects accompanying fall events. The observation of meteorite entry paths has shown that all meteorites are derived from orbits well within the inner part of our solar system, ${ }^{[17]}$ mainly from the asteroid belt. Deceleration from pre-entry velocities of 11.2 to $72 \mathrm{kms}^{-1}$ relative to Earth to terminal velocities of a few 100 $\mathrm{ms}^{-1}$ (depending upon size) occurs within a few seconds and leads to intense mechanical forces and frictional heating resulting in a partial or complete disruption and melting of the incoming meteoroids. Only meteorites that are larger than a certain minimum mass can survive atmospheric entry and fall to the ground. Fragmented meteorites form so-called meteorite showers resulting in strewnfields of typically elliptical shape that can extend for more than $50 \mathrm{~km}$. The lack of any observed trajectories from the outer solar system or even from beyond demonstrates the derivation of meteorites from our immediate cosmic neighbourhood, the asteroids, and in rare cases, Moon and Mars. The frequency of fall events is estimated at $\sim 80$ fall events per $10^{6}$ square kilometres ( $>10 \mathrm{~g}$ mass) per year, ${ }^{[18]}$ corresponding to 3.3 falls per year on the surface of Switzerland (last observed fall: Utzenstorf 1928).

\section{Types of Meteorites, Mineralogy and Parent Body Processes}

The classification of meteorites (Table 1), evolved from the description of a restricted number of meteorites, has proven to be not just descriptive, but based on true genetic relationships. Chondrites are meteorites built from materials, in still recognizable shape and composition, that predate the formation of large planetesimals. Some chondritic planetesimals underwent partial or complete melting, resulting in the formation of core, mantle and crust. Such differentiated materials constitute the nonchondritic part of the meteorites. Iron meteorites represent metallic core material. Mantle and crustal materials of different parent bodies form the achondrite group of meteorites. Parent body processes include metamorphism, melting and aqueous alteration. The most primitive meteorites, i.e. the ones closest to the composition of the solar nebula and the sun, are CI carbonaceous chondrites. Their composition is widely used as a reference to describe fractionation processes, e.g. in crustal and mantle rocks on Earth. The mineralogy of meteorites is broadly similar to that of terrestrial ultrabasic rocks (Table 2). Only a few meteoritic minerals are unknown on Earth, most of which originate from extremely reducing environments.

\subsection{Chondrites: Early Solar System History}

Chondrites are the most common class of meteorites (Fig. 1). Their name-giving constituents are the chondrules, spherical bodies typically 0.2 to $1 \mathrm{~mm}$ in diameter (Fig. 2). They consist of partially recrystallized $\mathrm{Mg}$,Fe-rich glass and are set in a finegrained matrix. Chondrites of the Ivunatype (CI) consist only of fine-grained serpentine matrix lacking chondrules. While the matrix of chondrites can be regarded as the most pristine leftover of the solar nebula, chondrules are drops of former silicate melt formed by melting of dust in the solar nebula. A third major constituent of many chondrites types is iron-nickel metal. After assembly to asteroids, chondritic material has undergone various levels of metamorphism ranging from weak recrystallization of glass to complete recrystallization and partial melting.

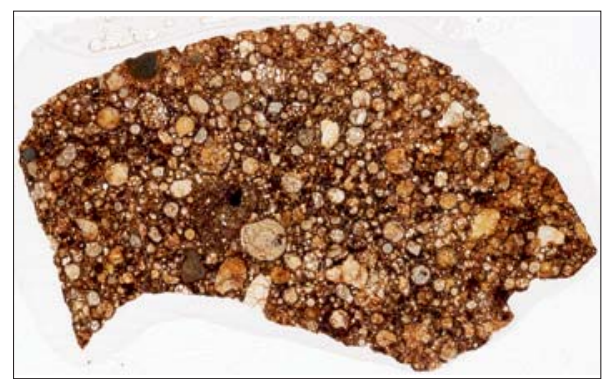

Fig. 1. Thin section of an ordinary chondrite found in the desert of Oman in 2010, showing the characteristic texture of densely packed chondrules. Image width is $37 \mathrm{~mm}$.

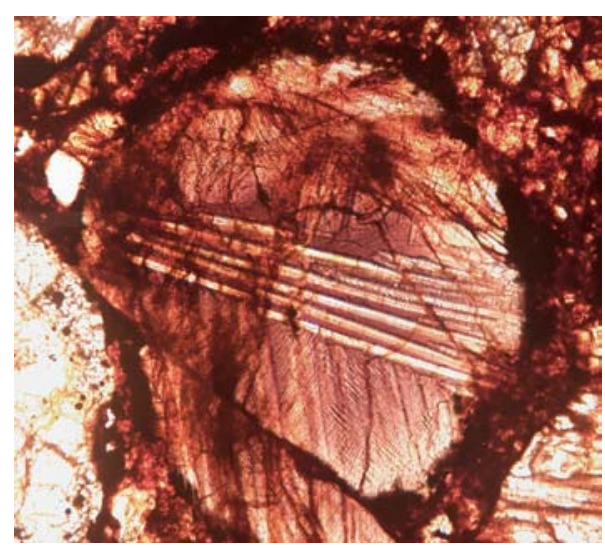

Fig. 2. Detail of a chondrule from Fig. 1 showing dendritic olivine crystals in glass, indicative of low metamorphism on the parent body. The texture is typical for rapid cooling $\left(\sim 100^{\circ} \mathrm{C} / \mathrm{h}\right)$ of silicate melt droplets that freely floated in the solar nebula. Irregular staining is due to terrestrial alteration. Diameter of the chondrule is $0.7 \mathrm{~mm}$.

Table 1. Classification of meteorites

\section{Undifferentiated meteorites (chondrites)}

- Carbonaceous chondrites (Cl, CM, CO, CV, CK, CR, CH, CB)

- Ordinary chondrites $(H, L, L L)$

- Enstatite chondrites (EH, EL)

- Rumuruti chondrites (R)

- Kakangari chondrites $(\mathrm{K})$

\section{Partly differentiated meteorites (primitive achondrites)}

- Acapulcoites, lodranites, winonaites, brachinites: Composition close to ordinary chondrites, but strongly recrystallized

- Ureilites: Carbon-containing, metamorphosed carbonaceous chondrites

\section{Differentiated meteorites}

Subgroup achondrites

- HED-meteorites: Howardites, Eucrites, Diogenites, probably from Vesta

- Aubrites: Enstatite achondrites, reduced, related to E chondrites

- Angrites: Basaltic rocks

- Mars meteorites (Shergottites, Nakhlites, Chassignites, orthopyroxenite)

- Lunar meteorites (Anorthositic breccias, Mare basalts, KREEP-rocks, and more)

Subgroup iron meteorites

- Iron meteorites: 14 chemical groups showing three types of textures (hexaedrites, octaedrites, ataxites)

Subgroup stony-iron meteorites

- Pallasites (core-mantle boundary or impact-mixed; related to irons)

- Mesosiderites (impact breccias, related to irons and HED) 
Table 2. Important phases in meteorites with key characteristics

\begin{tabular}{|c|c|}
\hline Olivine & $(\mathrm{Mg}, \mathrm{Fe})_{2} \mathrm{SiO}_{4}$ \\
\hline Enstatite & $(\mathrm{Mg}, \mathrm{Fe}) \mathrm{SiO}_{3}$ \\
\hline Plagioclase & $(\mathrm{Ca}, \mathrm{Na}, \mathrm{K}) \mathrm{Al}\left(\mathrm{Al}, \mathrm{Si}^{3}\right) \mathrm{Si}_{2} \mathrm{O}_{8}$ \\
\hline Kamacite & $\alpha-(\mathrm{Fe}>\mathrm{Ni})( \pm \mathrm{Si})$ \\
\hline Taenite & $\gamma-(\mathrm{Fe}, \mathrm{Ni})$ \\
\hline Troilite & FeS \\
\hline Serpentine & $\sim \mathrm{Mg}_{3} \mathrm{Si}_{2} \mathrm{O}_{5}(\mathrm{OH})_{4}$ \\
\hline Chromite & $(\mathrm{Mg}, \mathrm{Fe}) \mathrm{Cr}_{2} \mathrm{O}_{4}$ \\
\hline Magnetite & $\mathrm{Fe}_{3} \mathrm{O}_{4}$ \\
\hline Graphite & $\mathrm{C}$ \\
\hline Diamond & C \\
\hline Chlorapatite & $\mathrm{Ca}_{5}\left(\mathrm{PO}_{4}\right)_{3} \mathrm{Cl} \quad( \pm \mathrm{REE})$ \\
\hline Zircon & $\mathrm{ZrSiO}_{4}( \pm \mathrm{U}, \mathrm{Th})$ \\
\hline Tridymite & $\mathrm{SiO}_{2}$ \\
\hline Hibonite & $\mathrm{CaAl}_{12} \mathrm{O}_{19}$ \\
\hline Sinoite & $\mathrm{Si}_{2} \mathrm{~N}_{2} \mathrm{O}$ \\
\hline Niningerite & MgS \\
\hline
\end{tabular}

Most common silicate in meteorites

Common meteoritic silicate

In chondrites and achondrites, main carrier of alkalies in meteorite

In chondrites, irons etc, Si indicative of very reduced meteorites

In chondrites, irons

In chondrites, irons

Main constituent of $\mathrm{Cl}$ and $\mathrm{CM}$ chondrites

Common in many types, weathering-resistant

In the matrix of $\mathrm{C}$ chondrites

Common in low abundance in many meteorite types

Pre-solar in carbonaceous chondrites, shock-produced in ureilites, irons Important carrier of REE in meteorites

Occurs in HED's, mesosiderites and lunar meteorites, important for dating

Occurs in HED's, mesosiderites and lunar meteorites

In Ca-Al-rich inclusions (CAl's) representing solar system's oldest material In highly reduced meteorites (E-chondrites, aubrites), unknown from Earth In highly reduced meteorites (E-chondrites, aubrites), unknown from Earth

Non-crystalline substances

$\begin{array}{ll}\text { Melt glass } & \mathrm{Mg}-\mathrm{Fe}-\mathrm{Si}-\mathrm{Al}-\mathrm{Na}-\mathrm{O} \\ \text { 'Maskelynite' } & \mathrm{CaAl}_{2} \mathrm{Si}_{2} \mathrm{O}_{8}-\mathrm{NaAISi}_{3} \mathrm{O}_{8}( \pm \mathrm{K}) \\ \text { Carbonaceous material } & \mathrm{C}-\mathrm{N}-\mathrm{O}, \text { dominantly aromatic }\end{array}$

Important constituent of non-metamorphosed chondrules

Diaplectic plagioclase glass in strongly shocked meteorites

Important constituent in carbonaceous chondrites, partially(?) of pre-solar origin

\subsection{Iron Meteorites: Asteroid Cores}

Differentiation on planetoids in many cases led to complete melting and gravitative differentiation. Fe-Ni-metal present in precursor chondritic materials formed asteroid cores, fragments of which are the iron meteorites. Iron meteorites show a great variability expressed both in texture and composition. The large compositional variability, in terms of $\mathrm{Ni}$ and trace elements, ${ }^{[19]}$ results from a combination of bulk oxidation state and effects of differential crystallization. Textures reflect exsolution processes during cooling, controlled by bulk Ni content resulting in variable amounts and textures of the iron phases kamacite and taenite.

\subsection{Primitive Achondrites}

Primitive achondrites represent chondritic parent bodies that have undergone extensive metamorphism resulting in recrystallization and partial melt extraction, but not in complete melting and differentiation as in the case of achondrites. The mineralogy is dominated by olivine and pyroxene. Carbon-phases are characteristic for the ureilites.

\subsection{Asteroidal Achondrites}

Differentiation processes on asteroids led to the development of three main groups of igneous rocks represented by HED meteorites (pyroxenites, gabbros and basalts, 934 known meteorites), aubrites (strongly reduced pyroxenites, 65 meteorites) and angrites (basalts, 17 meteorites). A general characteristic of these rocks is the low amount of metallic iron. The HED meteorites form a series consistent with the inferred composition of upper mantle and crust (including volcanic rocks) of a large asteroid and are likely derived from Vesta based on spectral (IR) characteristics.

\subsection{Mars Meteorites}

A group of achondrites has characteristics strongly indicating an origin from Mars, ${ }^{[20,21]}$ and almost certainly excluding another source. This clan, forming a homogeneous group in terms of oxygen isotope ratios, ${ }^{[22]}$ consists of basalts to gabbros (shergottites), clinopyroxenites (nakhlites), dunites (chassignites) and a single orthopyroxenite. As of spring 2010, 90 Mars meteorites are known that can be assigned to about 55 different fall events; 22 are Antarctic and 62 are hot desert finds.

\subsection{Lunar Meteorites}

The first lunar meteorite was recognized among Antarctic finds after the first return of lunar samples. Since then the collection of lunar meteorites has grown considerably. Currently 130 lunar meteorites representing approximately 70 fall events are known. Twenty nine lunar meteorites are from Antarctica, the remainder are hot desert finds (including 56 from Oman). Lunar meteorites represent the same rock types as known from the Apollo and Luna missions: Anorthosites and Mare basalts. Impact melt breccias formed from these rock types are also represented. A special chemical signature on the Moon are rocks highly enriched in incompatible elements, including $\mathrm{K}$, REE, $\mathrm{P}, \mathrm{U}$, Th, Zr, Ba, a geochemical affinity termed KREEP, repre- senting the residual liquid material in the solidifying lunar magma ocean. The meteorite SaU 169 from Oman represents one of the most KREEP-rich lithologies (Fig. 3). $[23,24]$

\subsection{The Role of Redox Chemistry on Meteorite Compositions}

Iron is the most important redox-active element in meteorites with an average concentration of $18.2 \mathrm{wt} \%$ in CI chondrites. The common minerals in meteorites (pyroxenes, olivine) can incorporate iron. The oxidation state of iron is critical in determining mineral compositions. In the highly reduced enstatite chondrites, essentially all iron is present as metal, resulting in Fe-free silicates. A high degree of oxidation results in Fe-rich silicates, for example in the $\mathrm{Ru}-$ muruti-type chondrites. The degree of oxidation of meteorite parent bodies is likely correlated with the former abundance of water, increasing with distance to the sun. Water-poor bodies remained reduced, while iron metal on water-rich bodies was oxidized by $\mathrm{H}_{2} \mathrm{O}$ and the resulting ferrous iron was incorporated into silicates.

\section{Impacts and their Products}

Impact processes are the only geological processes on asteroids and also are dominant on Mars and Moon. Not surprisingly, impact processes are of prime importance in the understanding of meteorites: Many meteorites are impact-altered rocks (breccias, melt-rich breccias, shocked rocks), often containing shock-produced 


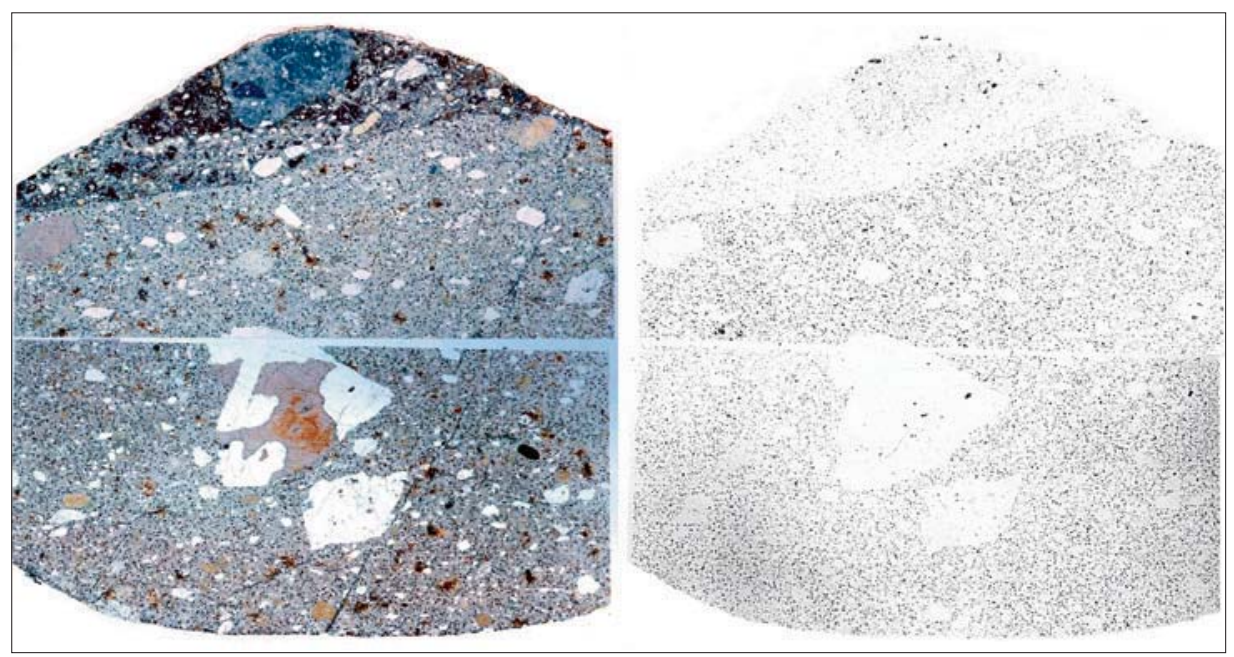

Fig. 3. Thin sections of lunar meteorite Sayh al Uhaymir 169 from Oman (left) and $\alpha$-autoradiographs (Kodak LR II film) of the same sections (right), demonstrating the high Thand U-content in the matrix of this KREEP-rich impact melt breccia. The majority of $\alpha$-emitters are grains of zircon containing several $100 \mathrm{ppm}$ of combined $U$ and Th. Bulk concentrations in the impact melt rock are $33 \mathrm{ppm}$ Th and $9 \mathrm{ppm} \mathrm{U}$. The top of the meteorite is formed by a lunar regolith with lower concentrations of Th and $U$. Width of sections is $45 \mathrm{~mm}$.

high-pressure phases. ${ }^{[25]}$ In principle the same impact effects that can be observed in meteorites are found in terrestrial rocks affected by the impact of large, crater-forming meteorites. Hypervelocity impacts lead to crater-forming explosions resulting in a near complete destruction of meteorites. Only in and near relatively small craters remnants of the impactor are found, often probably detached prior to impact.

\section{Meteorites and Astrobiology}

Without meteorites, the study of the origin, distribution and future of life in the Universe (astrobiology) would lack one of its important sources of information. The role of meteorites is in two major areas in this context: i) Study of pre-biotic chemistry, as represented by organic compounds in carbonaceous meteorites and interplanetary dust particles and ii) Mars meteorites, representing rocks from the planet in the solar system with the highest potential, apart from Earth, for extinct or extant life.

Organic compounds in meteorites are present in carbonaceous chondrites, some types of which contain up to $2 \%$ organically bound C. Numerous studies of observed falls of carbonaceous chondrites have demonstrated the presence of hundreds of organic compounds. ${ }^{[26]}$ These studies provided proof that organic synthesis on asteroids proceeded about as far as in the laboratory.[27]

Mars meteorites still are and will remain for a decade or more the only handson samples from the red planet. They are an excellent source, therefore, for information linking data from Mars missions with real rocks. Some Mars meteorites contain unambiguous evidence of pre-terrestrial low-temperature aqueous alteration, ${ }^{[28]}$ and it is a logical step to search for traces of possible Mars life in such meteorites. The limited success of 15 years of such studies, mainly concentrating on Mars orthopyroxenite ALH $84001^{[29,30]}$ may appear frustrating, as no generally accepted evidence of life has been found. However, such studies are a key for learning how to unravel the signatures of life.

\section{Weathering of Meteorites}

Freshly fallen meteorites mainly consist of minerals that are not in equilibrium with the Earth's oxidizing atmosphere and water. Weathering starts soon after arrival on Earth: ordinary chondrites often show macroscopic stainings of Fe-hydroxides after just a few days or weeks. The most susceptible phases are iron metal and phyllosilicates in carbonaceous chondrites. In Antarctica, weathering is very slow with some meteorites surviving more than 2 Ma. ${ }^{[31]}$ In hot desert environments, most meteorites have terrestrial ages of a few 10 '000 years. ${ }^{[32]}$ Metal is completely weathered within less than 20'000 years while troilite is more resistant but generally completely weathered in the oldest meteorites with terrestrial ages $>30$ '000 years. ${ }^{[16]}$ In all meteorites observed during studies in Oman, the weathering of olivine is relatively modest. Typically, weathered desert meteorites consist of a mixture of extraterrestrial minerals (olivine, pyroxene, plagioclase, chromite) and terrestrial oxidation products (mainly maghemite, magnetite, Fe-hydroxides and clay minerals). The texture typically remains well preserved. Chromite is the only extraterrestrial mineral retained in fossil meteorites from Ordovician sediments from Sweden. ${ }^{[33]}$

\section{The Potential of Meteorite Studies}

Meteorites have already provided a wealth of information about the early conditions and evolution of the solar system. Yet a very large potential remains, and future discoveries will be made due to the ongoing development of analytical techniques, the discovery of new meteorites and the advent of new ideas. Well-documented collections of meteorites form the basis of any such research. The development of a balance between good documentation and economic exploitation of meteorite search areas, including diligent management by the authorities involved, should be an important issue for the future.

\section{Acknowledgements}

This paper is largely based on experience gained through the Omani-Swiss meteorite project financed by the Swiss National Science Foundation (Nr 200020107681 and 200020-119937). The project is kindly supported by Salim Al-Ibrahim, Director General of Minerals, Minstry of Commerce and Industry, Muscat, Sultanate of Oman.

Received: June 6, 2010

[1] A. E. Rubin, J. N. Grossman, Meteorit. Planet. Sci. 2010, 45, 117.

[2] E. F. F. Chladni, 'Ueber den Ursprung der von Pallas gefundenen und anderer ihr ähnlichen Eisenmassen und über einige damit in Verbindung stehende Naturerscheinungen', J. F. Hartknoch, Riga, 1794.

[3] U. B. Marvin, in 'The history of meteoritics and key meteorite collections: Fireballs, falls and finds', Eds. G. J. H. McCall, A. J. Bowden, R. J. Howarth, Geological Society of London, London, 2006, p. 15

[4] M. Gounelle, in 'The history of meteoritics and key meteorite collections: Fireballs, falls and finds', Eds. G. J. H. McCall, A. J. Bowden, R. J. Howarth, Geological Society of London, London, 2006, p. 73.

[5] S. Russell, M. M. Grady, in 'The history of meteoritics and key meteorite collections: Fireballs, falls and finds', Eds. G. J. H. McCall, A. J. Bowden, R. J. Howarth, Geological Society of London, London, 2006, p. 153.

[6] F. Brandstätter, in 'The history of meteoritics and key meteorite collections: Fireballs, falls and finds', Eds. G. J. H. McCall, A. J. Bowden, R. J. Howarth, Geological Society of London, London, 2006, p. 123.

[7] A. Greshake, in 'The history of meteoritics and key meteorite collections: Fireballs, falls and finds', Eds. G. J. H. McCall, A. J. Bowden, R. J. Howarth, Geological Society of London, London, 2006, p. 135.

[8] C. L. V. Caillet Komorowski, in 'The history of meteoritics and key meteorite collections: Fireballs, falls and finds', Eds. G. J. H. McCall, 
A. J. Bowden, R. J. Howarth, Geological Society of London, London, 2006, p. 163.

[9] F. G. Houtermans, Il Nuovo Cimento 1953, 10, 1623.

[10] Meteoritical Bulletin Database, http://tin. er.usgs.gov/meteor/metbull.php, 2010.

[11] W. A. Cassidy, 'Meteorites, ice and Antarctica', Cambridge University Press, Cambridge, 2003.

[12] M. E. Zolensky, G. E. Wells, H. M. Rendell, Meteoritics 1990, 25, 11.

[13] A. W. R. Bevan, in 'The history of meteoritics and key meteorite collections: Fireballs, falls and finds', Eds. G. J. H. McCall, A. J. Bowden, R. J. Howarth, Geological Society of London, London, 2006, p. 325.

[14] A. W. R. Bevan, P. A. Bland, A. J. T. Jull, in 'Meteorites: Flux with time and impact effects', Ed. D. A. Rothery, Geological Society of London, London, 1998, p. 59.

[15] B. A. Hofmann, E. Gnos, A. Al-Kathiri, Proc. of the III European Workshop on ExoAstrobiology, Madrid, 10-20 Nov. 2003 (ESA SP-545), 2003, 73.

[16] A. Al-Kathiri, B. A. Hofmann, A. J. T. Jull, E. Gnos, Meteorit. Planet. Sci. 2005, 40, 1215.

[17] O. R. Norton, 'The Cambridge Encyclopedia of Meteorites', Cambridge University Press, Cambridge, 2002.

[18] I. Halliday, A. T. Blackwell, A. A. Griffin, Meteoritics 1989, 24, 173.

[19] J. T. Wasson, G. W. Kallemeyn, Geochim. Cosmochim. Acta 2002, 66, 2445.

[20] J. J. Papike, J. M. Karner, C. K. Shearer, P. V. Burger, Geochim. Cosmochim. Acta 2009, 73, 7443.

[21] A. H. Treiman, J. D. Gleason, D. D. Bogard, Planet. Space Sci. 2000, 48, 1213.

[22] R. N. Clayton, T. Mayeda, Geochim. Cosmochim. Acta 1996, 60, 1999.
[23] E. Gnos, B. A. Hofmann, A. Al-Kathiri, S. Lorenzetti, O. Eugster, M. J. Whitehouse, I. M Villa, A. J. T. Jull, J. Eikenberg, B. Spettel, U. Krähenbühl, I. A. Franchi, R. C. Greenwood, Science 2004, 305, 657.

[24] R. L. Korotev, Chem. Erde 2005, 65, 297.

[25] P. Gillet, A. El Goresy, P. Beck, M. Chen, Geological Society of America Special Papers 2006, $421,57$.

[26] M. A. Sephton, Nat. Product Rep. 2002, 19, 292.

[27] A. Lazcano, J. L. Bada, Origins Life Evol. Biospheres 2004, 33, 235.

[28] T. D. Swindle, A. H. Treiman, D. J. Lindstrom, M. K. Burkland, B. A. Cohen, J. A. Grier, B. Li, E. K. Olson, Meteorit. Planet. Sci. 2000, 35, 107.

[29] D. S. McKay, E. K. Gibson, K. L. ThomasKeprta, H. Vali, C. S. Romanek, S. J. Clemett, X. D. F. Chillier, C. R. Maechling, R. N. Zare, Science 1996, 273, 924

[30] D. S. McKay, K. L. Thomas-Keprta, S. J. Clemett, E. K. Gibson Jr., L. Spencer, S. J. Wentworth, in 'Instruments and Methods for Astrobiology and Planetary Missions XII', Proc. of SPIE Vol. 7441 744102-1, Eds. R. B. Hoover, G. V. Levin, A. Y. Rozanov, K. D. Retherford, 2009.

[31] K. C. Welten, L. Lindner, C. Alderliesten, K. van der Borg, Meteorit. Planet. Sci. 1999, 34, 559.

[32] A. J. T. Jull, in 'Meteorites and the Early Solar System II', Eds. D. S. Lauretta, H. Y. McSween, University of Arizona Press, Tucson, 2006, p. 889

[33] J. C. Bridges, B. Schmitz, R. Hutchison, R. C. Greenwood, M. Tassinari, I. A. Franchi, Meteorit. Planet. Sci. 2007, 42, 1781. 